\title{
Spatial and temporal immunocytochemical analysis of drosulfakinin (Dsk) gene products in the Drosophila melanogaster central nervous system
}

\author{
R. Nichols ${ }^{1,2}$, I.A. Lim ${ }^{2}$ \\ ${ }^{1}$ Department of Biological Chemistry, University of Michigan, Ann Arbor, MI 48109-1048, USA \\ 2 Department of Biology, University of Michigan, Ann Arbor, MI 48109-1048, USA
}

Received: 10 February 1995 / Accepted: 10 June 1995

\begin{abstract}
The spatial and temporal distribution of three peptides, DSK I, DSK II, and DSK 0, encoded by the Drosophila melanogaster drosulfakinin (Dsk) gene, have been examined in the central nervous system. DSK I and DSK II have a -RFamide C-terminus and are structurally similar to sulfakinin peptides; in contrast, DSK 0 contains -SFamide and is not structurally similar to sulfakinins. Antisera specificities were determined by the design of the antigens and confirmed by dot blot analysis and preincubation with peptides prior to their use in immunocytochemistry. The distribution of immunoreactivity suggests that all three DSK peptides are processed from the polypeptide precursor and expressed in many of the same cells. Expression was observed at all developmental stages with an increase in the level of staining and the number of immunoreactive cells as development progresses. Cells in the brain lobe, optic lobe, subesophageal ganglion, thoracic ganglia, and the eighth abdominal neuromere contain DSK-immunoreactive materials. Immunoreactive fibers project from some cells and extend into the brain and ventral ganglion with regions of extensive arborization. DSK 0 immunoreactivity provides initial evidence for the presence of a -SFamide peptide in neural tissue. The observed expression of DSK-immunoreactive materials throughout development in numerous cells of the central nervous system suggests that DSK peptides may serve as hormones, modulators, or transmitters involved in several functions.
\end{abstract}

Key words: FMRFamide - Cholecystokinin - Neuropeptides - Fruit fly, Drosophila melanogaster (Insecta)

This work was supported by a National Foundation grant (IBN 9409623) to R.N.

Correspondence to: R. Nichols

\section{Introduction}

Several studies have established that peptides present in the central nervous system can act as hormones, modulators, or transmitters of important physiological functions (Krieger 1983). In recent years numerous neuropeptides have been detected by bioassays, immunocytochemistry, and radioimmunoassays. Further studies to isolate and determine the structures of these peptides have resulted in the finding that these neuropeptides can frequently be grouped into families based on structure or activity, and that invertebrate and vertebrate neural tissue often contain homologous peptides.

One family of peptides, the sulfakinins, is related by structure and activity. Two sulfakinin peptides, leucosulfakinin (LSK) and leucosulfakinin II (LSK II), were identified from cockroach brain tissue by means of a gut motility assay (Nachman et al. 1986a, b). Subsequently, sulfakinin peptides have been isolated from other insects including the cockroach Periplaneta americana (Veenstra 1990), the locust Locusta migratoria (Schoofs et al. 1990), the fruit fly Drosophila melanogaster (Nichols 1992a), and the flesh fly Neobellieria bullata (Fonágy et al. 1992).

Sulfakinin peptides are members of a larger family of peptides with a common C-terminal RFamide structure. In addition, sulfakinin peptides are homologous to the vertebrate neuropeptide cholecystokinin (CCK) based on structure similarity and the requirement for a sulfated tyrosyl residue to induce gut motility (Nachman et al. 1986a, b).

Peptides containing -RFamide have been shown to be abundant, widely distributed peptides involved in important physiological functions (Raffa 1988). Using antisera to FMRFamide, the distribution of -RFamide peptides has been extensively studied in the Drosophila melanogaster central nervous system (White et al. 1986; Lundquist and Nässel 1990). In contrast, no prior immunocytochemical or peptide isolation study has reported the identification of a -SFamide peptide.

The Drosophila melanogaster sulfakinin gene can be predicted to encode three non-overlapping peptides: 
DSK I, DSK II, and DSK 0 (Nichols et. al. 1988). Based on nucleotide sequence and putative processing sites, the structures are: PheAspAspTyrGlyHisMetArgPheamide (DSK I), GlyGlyAspAspGlnPheAspAspTyrGlyHisMetArgPheamide (DSK II), and AsnGlnLysThrMetSerPheamide (DSK 0). DSK I and DSK II differ in structure by a five amino acid $\mathrm{N}$-terminal extension present in DSK II and share a high degree of structure homology with sulfakinin peptides isolated from other invertebrates. In contrast, DSK 0 is not similar in structure to sulfakinins, and no structural homologue has been isolated, suggesting that DSK 0 may be a novel peptide.

Our study of the Drosophila melanogaster sulfakinin peptides has included the isolation of DSK I and detection of DSK-specific immunoreactive material in larval neural tissue (Nichols 1992a). In this manuscript we report the spatial and temporal expression patterns of the DSK peptides in the Drosophila melanogaster central nervous system using antisera raised to antigens distinguishing DSK II from DSK I and DSK 0, and DSK 0 from DSK I and DSK II, and antisera raised to DSK I. The data presented here indicate that DSK-immunoreactive materials are present throughout development in several cell bodies in the brain lobe, optic lobe, subesophageal ganglion, thoracic ganglia, and an abdominal ganglion, and immunoreactive fibers that project from some of these cells that extend to the brain and ventral ganglion.

\section{Materials and methods}

\section{Staging flies}

Drosophila melanogaster Oregon R flies were raised on cornmeal molasses medium and maintained at $25^{\circ} \mathrm{C}$. At each developmental stage, neural tissue was dissected from flies of a known age. Flies were collected for dissection based on the number of hours after egg laying for embryonic tissue, after hatching for larval tissue, after becoming white prepupae for pupal tissue, and after eclosing for adult tissue. No fewer than six tissue preparations were analyzed for each developmental time point.

\section{Antigen design and antisera production}

Peptides used as antigens were synthesized with an Applied Biosystems model 431 solid phase synthesizer, purified by preparative reversed-phase high performance liquid chromatography, and the structures confirmed by mass spectrometry.

Antisera were raised to the synthetic peptide PheAspAspTyrGlyHisMetArgPheamide (DSK I) as previously described (Nichols 1992a). The antisera were purified on a FMRFamide peptide affinity column to remove antisera to -MRFamide, a structure that DSK I and DSK II have in common with FMRFamide-containing peptides. To ensure the removal of antisera recognizing MRFamide, the binding capacity of the resin was higher than the amount of antisera applied and the antisera were passed over the column several times. Antisera that did not bind to the FMRFamide peptide column were characterized by means of a solid phase dot blot assay. Since these antisera were raised to an antigen present in both DSK I and DSK II, they are referred to as DSK I/II antisera. The DSK I/II antisera used in this study were a higher titer antisera than those used in a previously reported study (Nichols 1992a).
Antisera to DSK II were generated to the five amino acid Nterminal extension, GlyGlyAspAspGln, which distinguishes DSK II from DSK I. The antigen was made as a multiple antigenic peptide or MAP, in which multiple copies of the antigen are synthesized on a branched polylysyl core (Postnett and Tam 1989). A peptide affinity column containing GlyGlyAspAspGln-MAP coupled to Affi-gel 10 (Bio-Rad Labs) in dry dimethyl sulfoxide and $1 \%$ triethylamine was used to purify antisera to DSK II according to a previously described method (Nichols 1992a; McCormick and Nichols 1993). These antisera are referred to as DSK II antisera.

The antisera used to recognize DSK 0-immunoreactive material were raised to the synthetic peptide AsnGlnLysThrMetSerPheamide (DSK 0). For use as an antigen, the peptide was conjugated to succinylated thyroglobulin through the lysyl residue and N-terminus of the peptide by means of carbodiimide coupling with EDAC (Yamada et al. 1981). These antisera are referred to as DSK 0 antisera.

Antisera were raised in New Zealand white rabbits. The initial immunizations were by subcutaneous injections at multiple sites of a total of $0.5 \mathrm{mg}$ of antigen emulsified in Freund's complete adjuvant. Subsequent boosts were given every 2 weeks by subcutaneous injections of $0.5 \mathrm{mg}$ of antigen emulsified in incomplete Freund's adjuvant. Antisera titers were analyzed by indirect immunocytochemistry of whole-mount third-instar larval central nervous systems as previously described (McCormick and Nichols 1993).

\section{Immunocytochemistry.}

The data reported in this manuscript are from whole-mount tissue preparations in which the central nervous system was dissected cleanly away from other tissue. The tissue was dissected in cold Ringer's solution and prepared for indirect immunohistochemistry according to a previously published procedure (McCormick and Nichols 1993). Tissue was fixed in paraformaldehyde for $4 \mathrm{~h}$ or longer at $4^{\circ} \mathrm{C}$, washed in PTN $(0.5 \mathrm{M}$ sodium phosphate, $\mathrm{pH} 7.2$, containing $0.01 \%$ Triton $\mathrm{X}-100,0.1 \%$ bovine serum albumin (BSA), and $0.1 \%$ sodium azide), incubated for $2 \mathrm{~h}$ or longer at $4^{\circ} \mathrm{C}$ with primary antisera, washed extensively in PTN, incubated for $2 \mathrm{~h}$ or longer at $4^{\circ} \mathrm{C}$ with fluorescein isothiocyanate (FITC; Sigma) or indocarbocyanine (CY3; Jackson ImmunoResearch)-labeled goat anti-rabbit antisera, and washed extensively in PTN prior to viewing.

\section{Microscopy and data collection}

Fluorescence signal was imaged with a BioRad MRC600 scanning confocal microscope equipped with a $\mathrm{Kr}-\mathrm{Ar}$ laser and attached to a Nikon inverted microscope. Data were processed with Adobe Photoshop and transferred to slide film with a Macintosh Quadra 800 and Lasergraphics LFR-X.

\section{Results}

The nomenclature used to identify cells expressing DSK immunoreactive is from White et al. 1986; Schneider et al. 1991; O'Brien et al. 1991; McCormick and Nichols 1993; Tibbetts and Nichols 1993. Identification is based on position when compared to cells expressing FMRFamide-immunoreactive materials. The description of the number of immunoreactive cells in the central nervous system takes into account the observation that the cells and fibers were all bilaterally symmetric to the midline, 


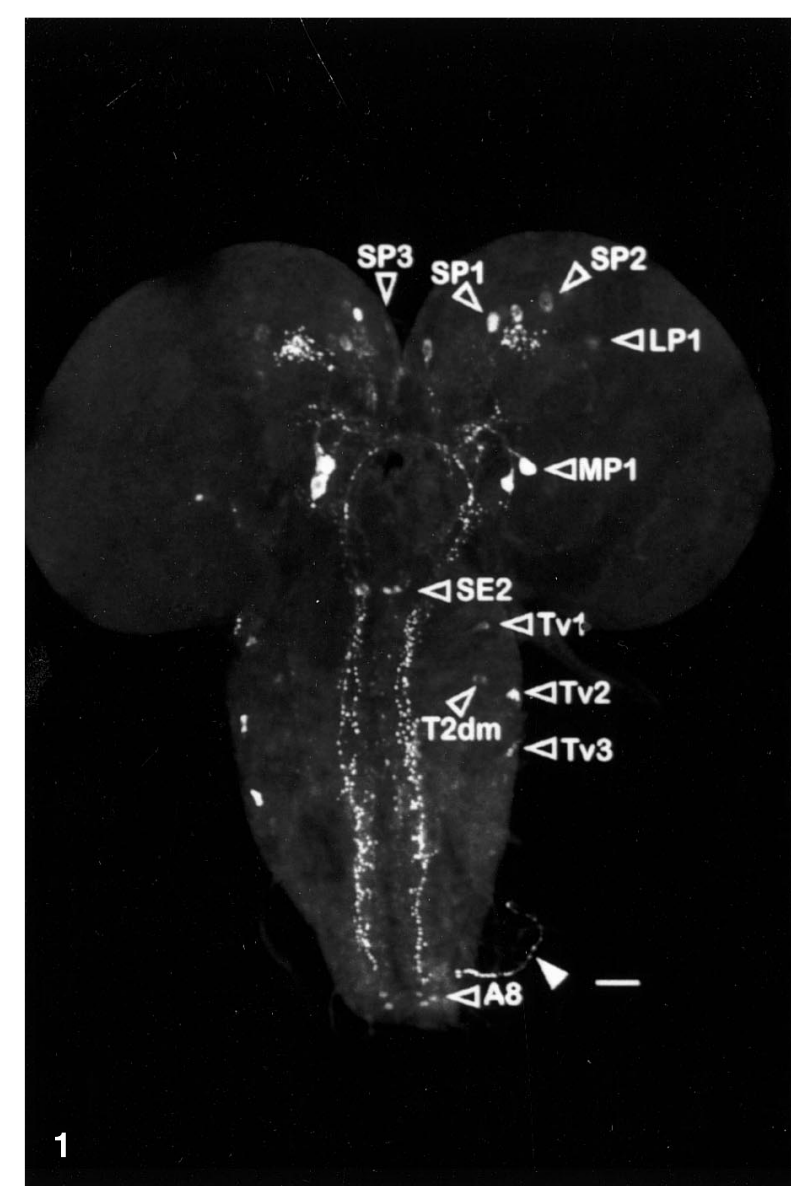

Fig. 1. DSK I/II immunoreactivity in larval neural tissue at $96 \mathrm{~h}$. Immunoreactive material is expressed in SP1, SP2, SP3, LP1, MP1, SE2, Tv1-3, T2dm, and A8 cells. An immunoreactive fiber projects away from the central nervous system in an abdominal ganglion (filled arrow). Bar: $50 \mu \mathrm{m}$

i.e., the report of immunoreactivity in one cell indicates that two immunoreactive cells, bilateral to the midline, were present. The staining patterns did not vary when comparing tissue dissected from females and males.

\section{Antisera specificity}

The specificity of each antisera was determined by the design of the antigen and confirmed by solid phase dot blot assay and by preincubation of the antisera with $10^{-4} \mathrm{M}$ and $10^{-6} \mathrm{M}$ synthetic peptide prior to use in immunocytochemistry. Antisera that did not bind to the FMRFamide peptide affinity column are DSK I/II-specific antisera and crossreact with DSK I and DSK II, but not DSK 0 or FMRFamide as analyzed by dot blot. Incubation of DSK I/II antisera with DSK 0 or FMRFamide prior to use in immunocytochemistry did not alter the pattern of immunoreactivity, while preincubation with DSK I or DSK II abolished all signal.

DSK II antisera recognize DSK II but not DSK 0, DSK I, or FMRFamide. Incubation of DSK II antisera

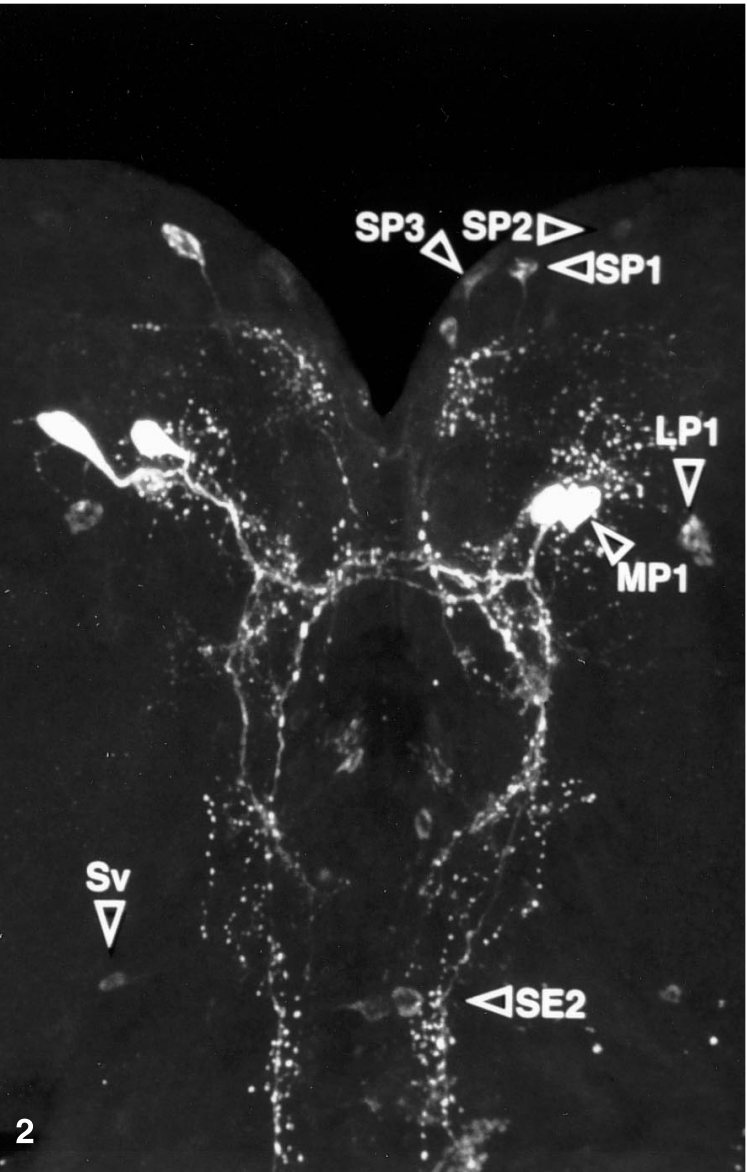

Fig. 2. DSK I/II immunoreactivity in larval protocerebrum and subesophageal ganglion at $96 \mathrm{~h}$. Immunoreactive material is expressed in SP1, SP2, SP3, LP1, MP1, Sv, and SE2 cells. Immunoreactive fibers project from the MP1 cells - one extends through the subesophageal ganglion into the ventral ganglion, while another crosses the midline, turns and extends through the subesophageal ganglion into the ventral ganglion. Bar: $50 \mu \mathrm{m}$

with DSK 0, DSK I, or FMRFamide prior to use in immunocytochemistry did not alter the pattern of immunoreactivity, while preincubation with GlyGlyAspAspGln abolished all signal.

DSK 0 antisera recognize DSK 0 but not DSK I, DSK II, or FMRFamide. Incubation of DSK 0 antisera with DSK I, DSK II, or FMRFamide prior to use in immunocytochemistry did not alter the pattern of immunoreactivity, while preincubation with DSK 0 abolished all signal. Preincubation of DSK 0 antisera with SFamide reduced the overall staining but did not abolish signal in any individual cell.

\section{DSK I/II immunoreactivity}

DSK I/II staining was first detected in neural tissue dissected from embryos at $16 \mathrm{~h}$. Weak but consistent signal was observed in one cell in the subesophageal ganglion (SE2) and two cells in the medial protocerebrum (MP1; data not shown). 

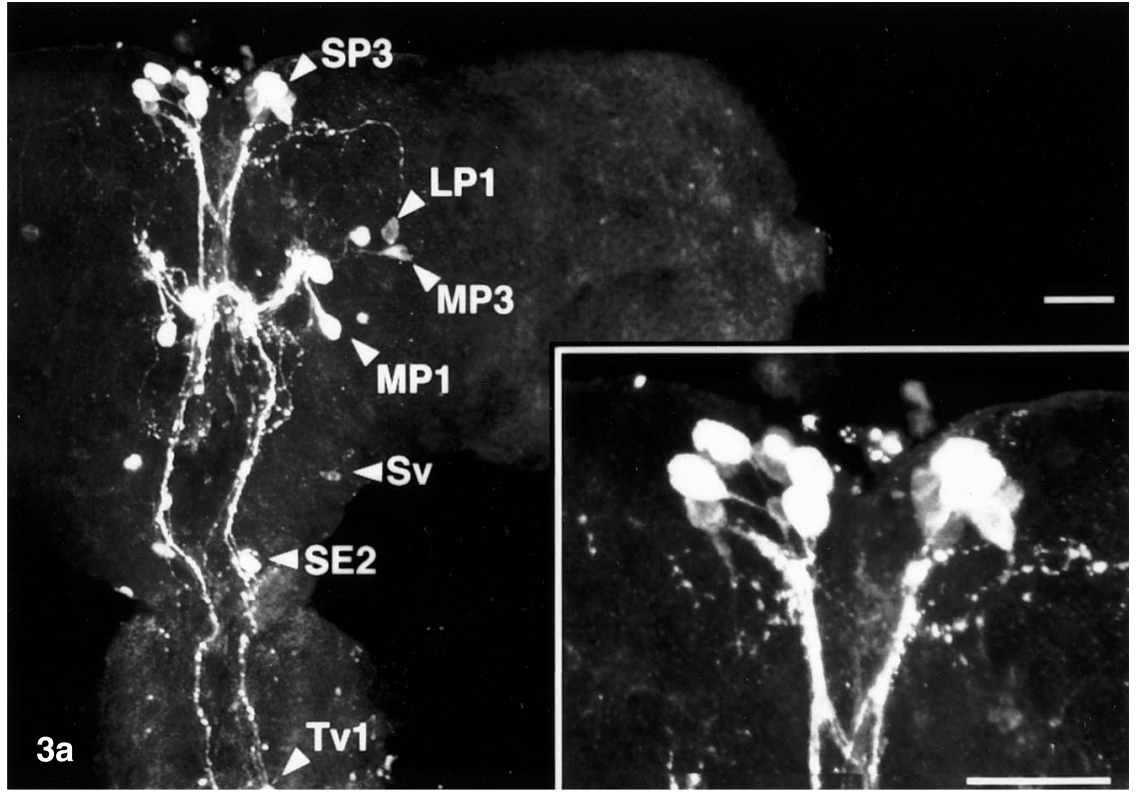

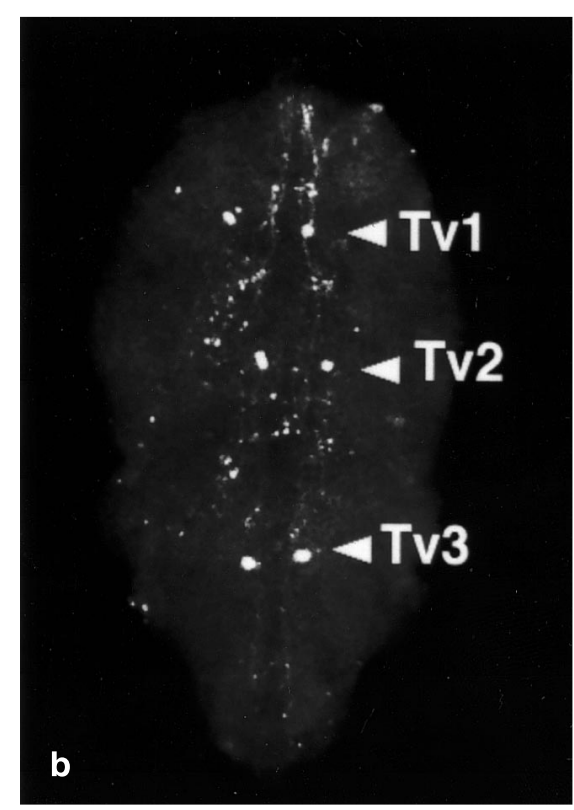

bers that project from the SP cells. b Immunoreactive material is expressed in Tv1-3 cells in the pupal ventral ganglion at $80 \mathrm{~h}$. Bar: $50 \mu \mathrm{m}$
Immunoreactive material is expressed in SP3, LP1, MP1, MP3, Sv, and SE3 cells in pupal tissue at $24 \mathrm{~h}$. An enlargement (inset) of the superior protocerebrum illustrates the immunoreactive fi-

Numerous cells express DSK I/II-immunoreactive material in neural tissue dissected from larvae at $96 \mathrm{~h}$ (Fig. 1). Multiple cells in the superior protocerebrum (SP1, SP2, and SP3), two cells in the medial protocerebrum (MP1), one cell in the lateral protocerebrum (LP1), one cell in the subesophageal ganglion (SE2), one cell in each of the three thoracic ganglia (Tv1-3), and two cells in the eighth abdominal ganglion (A8) are stained. Faint signal is observed in one cell in the thoracic ganglion (T2dm), more medial than the Tv1-3 cells (Fig. 1), and one cell in the subesophageal ganglion (Sv), more lateral than the SE2 cell (Fig. 2). The same pattern of expression was observed in tissue dissected from larvae at $48 \mathrm{~h}$.

Immunoreactive fibers project from some cells of which the most striking are those that project from the MP1 cells. One immunoreactive fiber extends posteriorly to the ventral ganglion, while another extends medially, crosses over the midline, and continues posteriorly parallel to the midline to traverse the entire ventral ganglion and extend out of the central nervous system. The MP1 cells also send immunoreactive fibers anteriorly, passing close to the SP cells, with arborizations in the superior protocerebrum (Figs. 1 and 2).

The DSK I/II staining pattern in pupal neural tissue is similar to that observed in larval neural tissue (Figs. 3a, b). Multiple cells in the superior protocerebrum, two cells in the medial protocerebrum (MP1), one cell in the lateral protocerebrum (LP1), one cell in the subesophageal ganglion (SE2), another cell in the subesophageal ganglion (Sv), more lateral than the SE2 cell, and one cell in each of the three thoracic ganglia (Tv1-3) are stained. In addition, two cells in the medial protocerebrum (MP3), lateral to the MP1 cells, are stained. The intense signal and close proximity of the cells in the su- perior protocerebrum make it difficult to assess the number and identity of SP cells stained. In contrast to the expression pattern in larval tissue, no staining of the T2dm cell is observed, and the A8 cells are only weakly stained in pupae. There is an increase in the intensity of staining and complexity of the immunoreactive fibers that project from the SP and MP1 cells (Fig. 3a). Immunoreactive fibers that project from the SP cells extend into the medial protocerebrum (Fig. 3a). The same pattern of expression was observed for tissue dissected from pupae at $24 \mathrm{~h}$ and $80 \mathrm{~h}$.

The cellular distribution of DSK I/II antisera staining in adult neural tissue is similar to that observed in larval and pupal neural tissue; however, the intensity and complexity of the immunoreactive fibers increases significantly (Fig. 4). Multiple cells in the superior protocerebrum, two cells in the medial protocerebrum (MP1), two

Fig. 4. DSK I/II immunoreactivity in adult neural tissue at 7 days. Immunoreactive material is expressed in SP, LP1, MP1, MP3, Sv, SE2, Tv1-3, and A8 cells. Immunoreactive fibers that project from the MP1 cells extend into the optic lobe, superior protocerebrum, subesophageal ganglion, and ventral ganglion. Immunoreactive fibers that project from the SE2 cell extend into the ventral ganglion. Bar: $50 \mu \mathrm{m}$

Fig. 5. DSK II immunoreactivity in larval neural tissue at $48 \mathrm{~h}$. Immunoreactive material is expressed in the MP1, SE2, and Tv1-3 cells. Bar: $50 \mu \mathrm{m}$

Fig. 6. DSK II immunoreactivity in pupal neural tissue 48 h. Immunoreactive material is expressed in the MP1, SE2, and Tv1-3 cells. Bar: $50 \mu \mathrm{m}$

Fig. 7. DSK II immunoreactivity in adult neural tissue 7 days. Immunoreactive material is expressed in the LP1, MP1, MP3, SE3, T2dm, and Tv1-3 cells. Bar: $50 \mu \mathrm{m}$ 


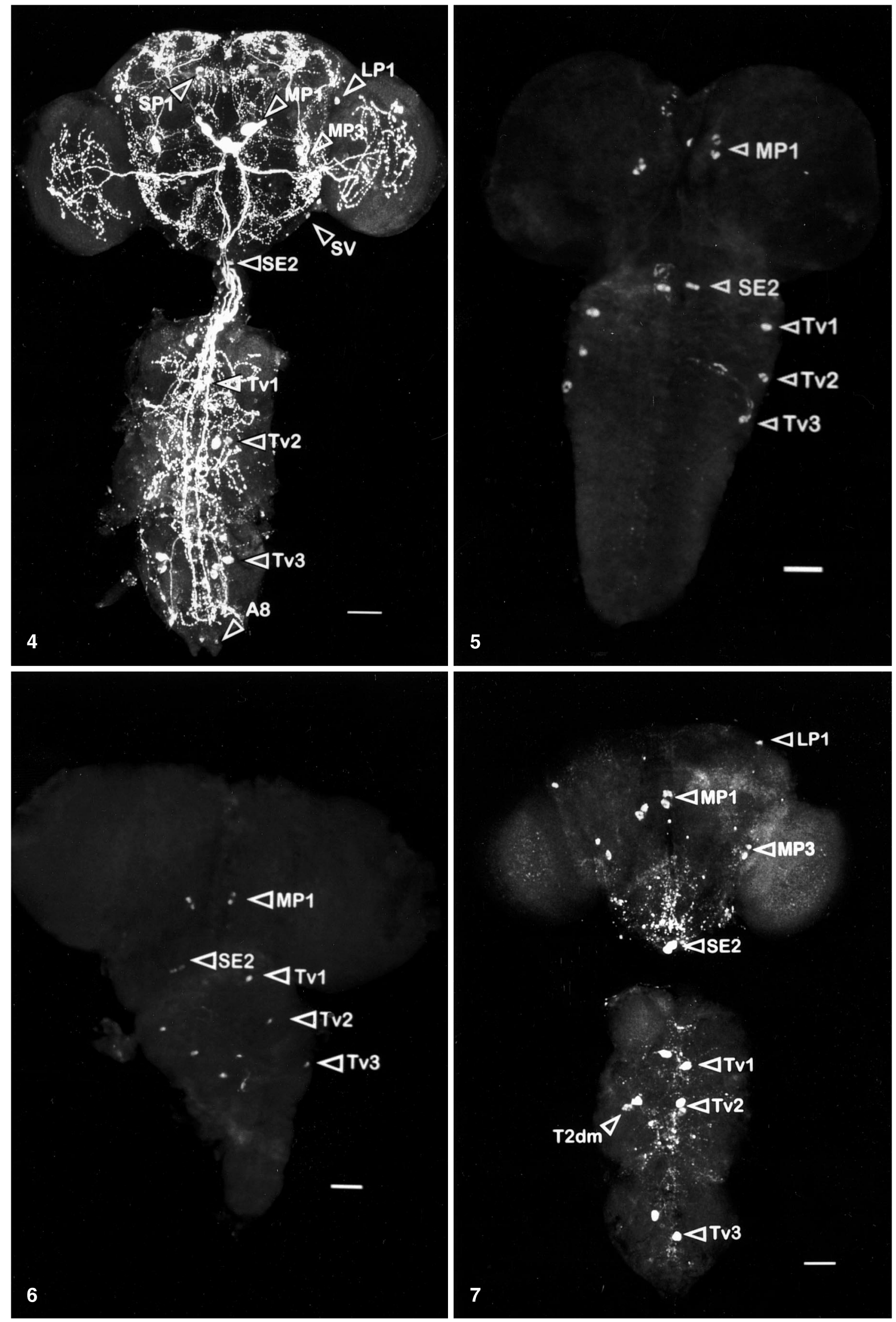



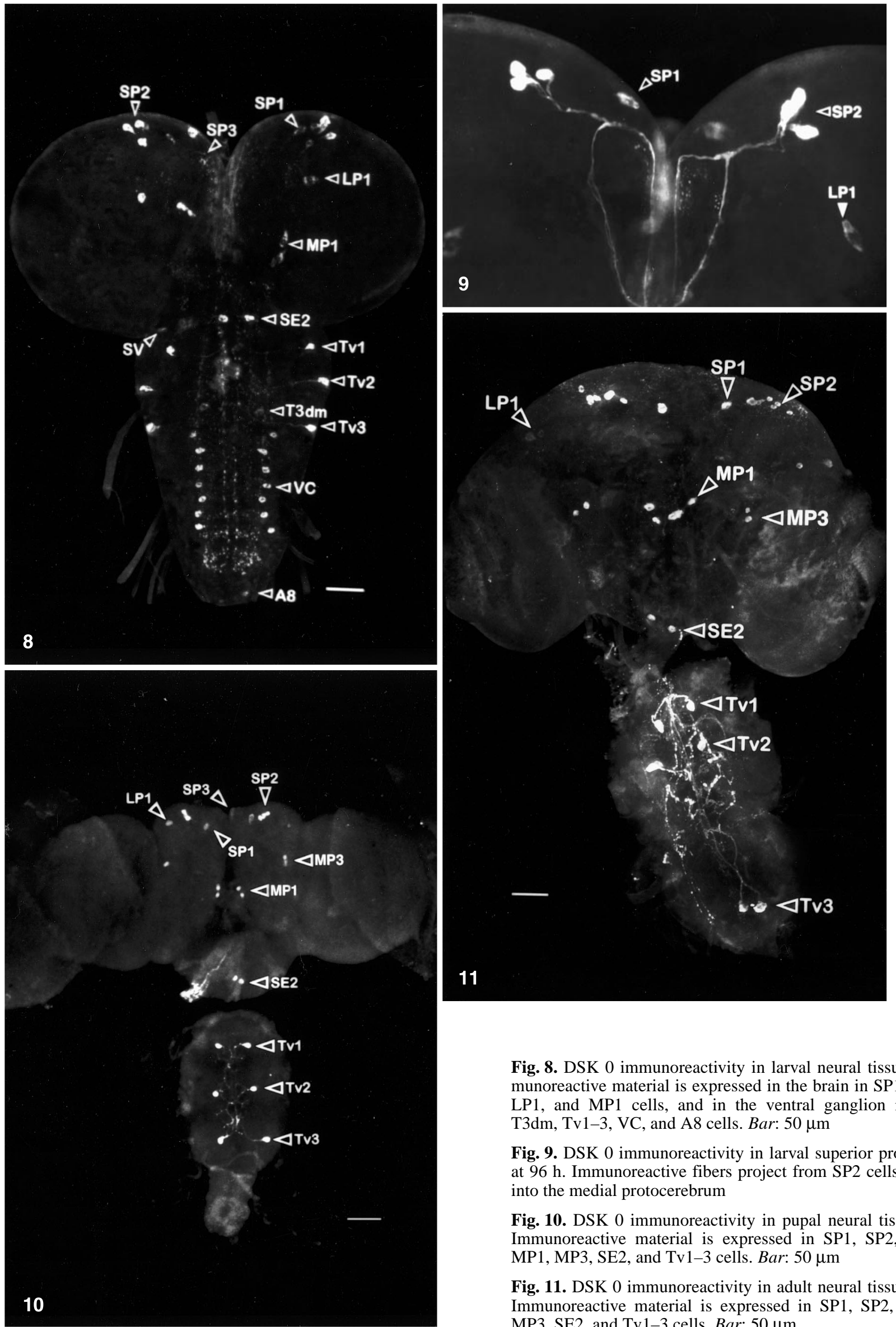

Fig. 8. DSK 0 immunoreactivity in larval neural tissue $96 \mathrm{~h}$. Immunoreactive material is expressed in the brain in SP1, SP2, SP3, LP1, and MP1 cells, and in the ventral ganglion in SE2, Sv, T3dm, Tv1-3, VC, and A8 cells. Bar: $50 \mu \mathrm{m}$

Fig. 9. DSK 0 immunoreactivity in larval superior protocerebrum at $96 \mathrm{~h}$. Immunoreactive fibers project from SP2 cells and extend into the medial protocerebrum

Fig. 10. DSK 0 immunoreactivity in pupal neural tissue at $48 \mathrm{~h}$. Immunoreactive material is expressed in SP1, SP2, SP3, LP1, MP1, MP3, SE2, and Tv1-3 cells. Bar: $50 \mu \mathrm{m}$

Fig. 11. DSK 0 immunoreactivity in adult neural tissue at 7 days. Immunoreactive material is expressed in SP1, SP2, LP1, MP1, MP3, SE2, and Tv1-3 cells. Bar: $50 \mu \mathrm{m}$ 
cells in the medial protocerebrum (MP3), lateral to the MP1 cells, one cell in the lateral protocerebrum (LP1), one cell in the subesophageal ganglion (SE2), one cell in the subesophageal ganglion (Sv), more lateral than the SE2 cell, and one cell in each of the three thoracic ganglia (Tv1-3) are stained. The intense signal from the immunoreactive fibers and numerous varicosities in the superior protocerebrum make it difficult to assess the number and identity of SP cells stained. In contrast to the expression pattern in larval neural tissue, only one A8 cell and no staining of the T2dm cell is observed; however, the complexity and intensity of the immunoreactive fibers present in the ventral ganglion could easily have obscured the presence of a A 8 cell and a T2dm cell.

In the adult, the immunoreactive fibers extending from the MP1 cells are similar to those observed in both the larva and pupa; however, the complexity and level of staining has increased markedly in the medial and superior protocerebrum and the thoracic ganglion. In addition, an immunoreactive fiber that extends from the MP1 cells projects to the optic lobe and then branches with extensive arborization throughout it.

\section{DSK II immunoreactivity}

DSK II-immunoreactive material was first detected in tissue dissected from larvae (Fig. 5). Two medial protocerebrum cells (MP1), one subesophageal ganglion cell (SE2), and one cell in each of the three thoracic ganglia (Tv1-3) are stained. Faint signal is observed in fibers that project from the MP1 cells, extend medially, cross over the midline, and continue posteriorly extending along the midline into the ventral ganglion. The MP1 cells also send immunoreactive fibers anteriorly with arborizations in the superior protocerebrum. The pattern of expression was the same for tissue dissected from larvae at $24 \mathrm{~h}$ and $96 \mathrm{~h}$ (data not shown).

The DSK II staining pattern in pupal neural tissue is similar to that observed in larval neural tissue (Fig. 6). Two medial protocerebrum cells (MP1), one subesophageal ganglion cell (SE2), and one cell in each of the three thoracic ganglion (Tv1-3) are stained. The pattern of expression was the same for tissue dissected from pupae at $24 \mathrm{~h}$ and $48 \mathrm{~h}$ (data not shown).

The DSK II staining pattern in adult neural tissue is similar to that observed in larval and pupal neural tissue (Fig. 7). Two medial protocerebrum cells (MP1), one subesophageal ganglion cell (SE2), and one cell in each of the three thoracic ganglia (Tv1-3) are stained. In addition to those cells that have stained in both larval and pupal neural tissue, one lateral protocerebrum cell (LP1), and two cells in the medial protocerebrum (MP3), lateral to the MP1 cells, are stained.

\section{DSK 0 immunoreactivity}

DSK 0 staining is first detected in neural tissue dissected from embryos at 13-16 h. Faint signal is observed in a cell in the subesophageal ganglion (SE2) and two cells in the medial protocerebrum (MP1; data not shown).

Numerous cells express DSK 0-immunoreactive material in neural tissue dissected from larvae at $96 \mathrm{~h}$ (Fig. 8). The staining pattern was the same for tissue dissected from larvae at $50 \mathrm{~h}$ and $96 \mathrm{~h}$. Multiple cells in the superior protocerebrum (SP1, SP2, and SP3), two cells in the medial protocerebrum (MP1), one cell in the lateral protocerebrum (LP1), one cell in the subesophageal ganglion (SE2), one cell in each of the three thoracic ganglion (Tv1-3), one cell more medial than the three thoracic ganglion cells (T3dm), and seven cells positioned in a line or chain parallel to the midline in the ventral ganglion (VC) are stained. One cell in the eighth abdominal ganglion (A8) and one cell in the subesophageal ganglion (Sv), lateral to the SE2 cell, stain less intensely. The staining of SP1, SE2, and Tv1-3 cells was observed in tissue dissected from larvae at $10 \mathrm{~h}$ (data not shown) and SP2 and VC cells, as well as SP1, SE2, and Tv1-3 cells, were observed in tissue dissected from larvae at $20 \mathrm{~h}$ (data not shown).

Immunoreactive fibers projecting from all three SP2 cells are characteristic of DSK 0 antisera staining (Fig. 9). These fibers extend medially and posteriorly parallel to the midline, while other fibers appear to branch from these SP2 tracts and project posteriorly at a more lateral point than the first set of tracts.

The DSK 0 staining pattern in pupal tissue is similar to that observed in larval neural tissue (Fig. 10). Multiple cells in the superior protocerebrum (SP1, SP2, and SP3), two cells in the medial protocerebrum (MP1), one cell in the lateral protocerebrum (LP1), one cell in the subesophageal ganglion (SE2) and another more lateral cell $(\mathrm{Sv})$, and one cell in each of the three thoracic ganglia (Tv1-3) are stained. In contrast to the expression pattern in larval tissue, no staining of $\mathrm{Sv}, \mathrm{T} 3 \mathrm{dm}, \mathrm{VC}$, or A8 cells is observed, while two cells (MP3) in the medial protocerebrum, more lateral than the MP1 cells, are stained. In addition, there is an increase in signal intensity and arborization of the immunoreactive fibers in the thoracic ganglia. The SE2, Tv1-3, MP1, SP2, SP3, and LP1 cells are stained in tissue dissected from pupae at $48 \mathrm{~h}$ and $72 \mathrm{~h}$. However, the staining of the MP3 cell, observed in tissue dissected from pupae at $48 \mathrm{~h}$ and $72 \mathrm{~h}$, is not present in tissue dissected from pupae at $24 \mathrm{~h}$ (data not shown).

The DSK 0 staining in adult tissue is similar to that observed in larval and pupal neural tissue (Fig. 11). Multiple cells in the superior protocerebrum (SP1, SP2, and SP3), two cells in the medial protocerebrum (MP1), one cell in the lateral protocerebrum (LP1), two cells (MP3) in the medial protocerebrum, lateral to the MP1 cells, one cell in the subesophageal ganglion (SE2), and one cell in each of the three thoracic ganglia (Tv1-3) are stained. In contrast to the expression pattern in larval tissue, no staining of $\mathrm{Sv}, \mathrm{T} 3 \mathrm{dm}, \mathrm{VC}$, or A8 cells is observed.

In this manuscript, cells are identified based on position when comparing DSK and FMRFamide staining or the individual DSK peptide expression patterns; however, our preliminary double-label immunocytochemical 
studies indicate that these assignments are correct. For instance, those cells stained by each of the three DSK antisera are also stained by FMRFamide antisera, and cells stained by DSK II are stained by DSK I/II antisera.

\section{Discussion}

To study the structure and expression of Drosophila neuropeptides, we have isolated the naturally occurring peptides and raised antisera to the peptides. The generation

of sequence-specific antisera to Drosophila neuropeptides provides the opportunity to study the expression of the individual peptides, as well as to determine whether structurally related peptides are co-expressed. In addition, sequence-specific antisera serve as valuable tools for the analysis of Drosophila mutants in studying the function and the regulation of expression of neuropeptides.

In this manuscript we describe the spatial and temporal expression of DSK neuropeptides using antisera raised to three different antigens. It is important to note

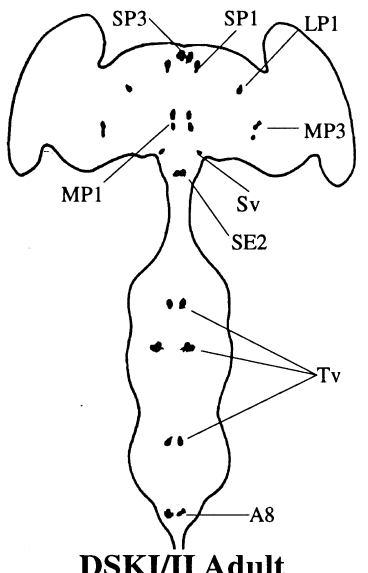

DSKI/II Adult

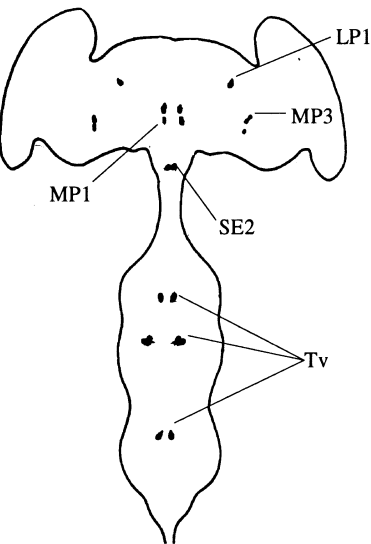

DSKext Adult

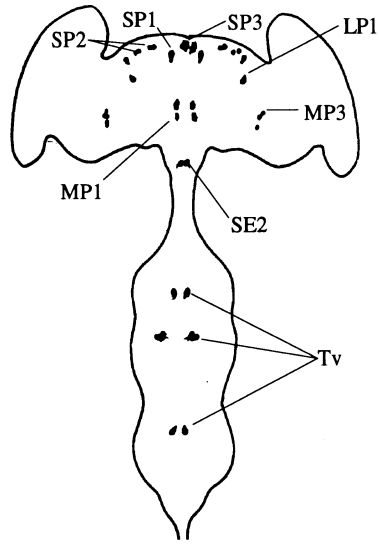

DSK0 Adult
Fig. 12. Schematic illustration of DSK I/II- and DSK II-immunoreactive materials in Drosophila melanogaster. The cellular distribution of immunoreactive material is illustrated for all stages of development

Fig. 13. Schematic illustration of DSK 0-immunoreactive material in Drosophila melanogaster. The cellular distribution of immunoreactive material is illustrated for all stages of development 
that there is a limitation in interpreting the immunocytochemical data presented because of the structure similarity between DSK I and DSK II. Since the polyclonal antisera raised to DSK I detect both DSK I and DSK II, a cell stained by both DSK I/II antisera and DSK II antisera may contain DSK I and DSK II, or DSK II alone. We cannot resolve this ambiguity; however, the data reported using DSK I antisera and DSK II antisera do contribute to the current understanding of sulfakinin expression.

Expression of DSK-immunoreactive material begins in the embryo and continues with an increase in the number of cells stained and an increase in the intensity of staining, as well as an increase in arborization of the immunoreactive fibers. DSK I/II immunoreactivity is expressed in cell bodies and fibers in the brain lobe, optic lobe, subesophageal ganglion, thoracic ganglia, and an abdominal ganglion. In addition, we observed an intensely staining immunoreactive fiber that projects from an abdominal ganglion in larval tissue to an, as yet, unidentified target site.

DSK II-immunoreactive material is present in Drosophila melanogaster neural tissue throughout postembryonic development. The cellular distribution of DSK II immunoreactivity is a subset of those cells stained by DSK I/II antisera (Fig. 12). These results can be interpreted to indicate that those cells stained by DSK I/II antisera, but not stained by DSK II antisera, express DSK I but not DSK II, suggesting that the drosulfakinin precursor may undergo cell-specific processing. Alternative explanations are that the amount of DSK II expressed in some cells is lower than our detection level or that DSK II is released more rapidly than DSK I.

The staining of cells with DSK II antisera suggests that DSK II is expressed, a finding that is consistent with our peptide isolation study to identify -RFamide-immunoreactive materials in Drosophila melanogaster in which N-terminal sequence data for DSK II were obtained (Nichols, 1992a, b). The amount of DSK II recovered in the peptide isolation study was substantially lower than for DSK I, an observation that is consistent with the level of staining observed with DSK I/II antisera and DSK II antisera.

DSK 0-immunoreactive material is expressed in Drosophila melanogaster neural tissue throughout development (Fig. 13). The specificity of DSK 0 antisera and the pattern of DSK 0 immunoreactivity suggests that DSK 0 or a DSK 0-like material is expressed in cells that contain DSK I and DSK II. Although the cellular distribution of DSK 0 immunoreactivity is similar to those cells stained by DSK I/II antisera, one striking difference exists - the staining of the VC cells by DSK 0 antisera. The VC cells or ventral chain of seven cells stain intensely and consistently with DSK 0 antisera. DSK 0 antisera preincubated with FMRFamide or SFamide also stain the VC cells; however, neither DSK I/II nor DSK II antisera stain the VC cells. In addition, the VC cells have been reported to be weakly and inconsistently stained with FMRFamide antisera (Schneider et al. 1991). Taken together, these results suggest that the VC cells contain DSK 0 or a peptide that is structurally more similar to DSK 0 than to FMRFamide, DSK I, or DSK II.
Our immunocytochemical data indicate that DSK I-, DSK II-, and DSK 0-immunoreactive materials are expressed in many of the same cells throughout development, e.g., the subesophageal ganglion cell (SE2), the two medial protocerebrum cells (MP2), the three thoracic cells (Tv1-3), the lateral protocerebrum cell (LP1), and the two lateral medial protocerebrum cells (MP3). However, some cells, e.g., a subesophageal cell (Sv), the abdominal ganglion cells (A8), and the ventral chain cells (VC), do not contain all three DSK peptides. Possible explanations for these differences in expression include cell-specific processing of the sulfakinin precursor, a difference in antisera titers, or the presence of structurally related antigens.

During development some cells no longer stained by DSK antisera, e.g., the VC cells, are stained only in larval tissue by DSK 0 antisera. Based on our current data, we do not know if the variation in staining results from cell death or regulation of expression.

Sulfakinin immunoreactivity in Calliphora vomitoria (Duve et al. 1994) is not similar to that observed in Drosophila melanogaster. While this observation may be species related, other potential reasons for the difference may be technical. For example, Duve et al. 1994 raised antisera to AspGinPheAspAspTyr $\left(\mathrm{SO}_{3} \mathrm{H}\right)$ GlyHisMetArgPheamide and distinguished immunoreactivity originating from sulfakinin from structurally related peptides by preincubating the antisera with FMRFamide prior to use in immunocytochemistry. In contrast, our DSK I/II antisera, produced to PheAspAspTyrGlyHisMetArgPheamide, were purified on a FMRFamide peptide affinity column to remove any antisera recognizing MRFamide, a structure shared by DSK I, DSK II, and FMRFamide-related peptides. Duve et al. 1994 detected only four pairs of sulfakininimmunoreactive cells in the entire Calliphora central nervous system - much like our initial study, which used low titer DSK-specific antisera and detected a limited number of cells in brain tissue (Nichols 1992a). Their polyclonal antisera, reported to have a high titer as detected by radioimmunoassay, may have contained a high percentage of RFamide antisera, or antisera not specific to sulfakinins, which would have bound FMRFamide during preincubation of the antisera prior to immunocytochemistry.

In this study we present data to support the conclusion that DSK II- and DSK 0-immunoreactive material, as well as DSK I, are expressed in Drosophila melanogaster neural tissue. The observed cellular expression of DSK-immunoreactive materials in the protocerebrum, optic lobe, subesophageal ganglion, thoracic ganglia, and an abdominal ganglion throughout development suggests that the DSK peptides may act as hormones, modulators, or transmitters in several functions. The extensive pattern of DSK-immunoreactive fibers connecting the thoracic and abdominal ganglia with the protocerebrum and subesophageal ganglion, as well as extensive arborization of immunoreactive fibers from the medial protocerebrum to the optic lobe, suggests an important role for DSK peptides in integrating or regulating large portions of the central nervous system. 
Acknowledgements. This study has been reported at the Genetics Society Annual Drosophila melanogaster Meeting (1993), the Society for Neuroscience Meeting (1993), and the Midwest Drosophila melanogaster Meeting (1994). The multiple antigenic peptides were synthesized and purified at the University of Michigan Carbohydrate and Protein Structure Facility (P.C. Andrews, Ph.D., Director). The authors thank P.C. Andrews for performing the dot blot assays, J.B. McCormick and J.B. Friedman for help in antisera production, and J.B. McCormick for scientific discussions.

\section{References}

Duve H, Rehfeld JF, East P, Thorpe A (1994) Localisation of sulfakinin neuronal pathways in the blowfly Calliphora vomitoria. Cell Tissue Res. 275:177

Fonágy A, Schoofs L, Proost P, Damme J van, DeLoof A (1992) Isolation and primary structure of two sulfakinin-like peptides from the flesh fly, Neobellieria bullata. Comp Biochem Physiol 103:135

Krieger D (1983) Brain peptides: what, where and why? Science 222:975

Lundquist CT, Nässel DR (1990) Substance P-, FMRFamide-, and gastrin/cholecystokinin-like immunoreactive neurons in the thoracico abdominal ganglia of the flies Drosophila and Calliphora. J Comp Neurol 294:161

McCormick J, Nichols R (1993) Spatial and temporal expression identify dromyosuppressin as a brain-gut peptide in Drosophila melanogaster. J Comp Neurol 3:279

Nachman RJ, Holman GM, Haddon WF, Ling N (1986a) Leucosulfakinin, a sulfated insect neuropeptide with homology to gastrin and cholecystokinin. Science 234:71

Nachman RJ, Holman GM, Cook BJ, Haddon WF, Ling N (1986b) Leucosulfakinin II, a blocked sulfated insect neuropeptide with homology to cholecystokinin and gastrin. Biochem Biophys Res Commun 140:357

Nichols R, Schneuwly SA, Dixon JE (1988) Identification of a Drosophila melanogaster homologue to the vertebrate neuropeptide cholecystokinin. J Biol Chem 263:12167
Nichols R (1992a) Isolation and expression of the Drosophila melanogaster drosulfakinin neural peptides product, DSK I. Cell Mol Neurosci 3:342

Nichols R (1992b) Isolation and structural characterization of TDVDHVFLRFamide and FMRFamide-containing neural peptides. J Mol Neurosci 3:213

O'Brien MA, Schneider LE, Taghert PH (1991) In situ hybridization of the FMRFamide neuropeptide gene in Drosophila II. Constancy in the cellular pattern of expression during metamorphosis. J Comp Neurol 304:623

Posnett DN, Tam JP (1989) Multiple antigenic peptide method for producing antipeptide site-specific antibodies. In: Langone JJ (ed) Methods in enzymology. Academic Press, New York, 178:739

Raffa RB (1988) The action of FMRFamide (Phe-Met-Arg-Phe$\mathrm{NH}_{2}$ ) and related peptides on mammals. Peptides 9:915

Schneider LE, O'Brien MA, Taghert PH (1991) In situ hybridization of the FMRFamide neuropeptide gene in Drosophila. I. Restricted expression in embryonic and larval stages. J Comp Neurol 304: 608

Schoofs L, Holman GM, Hayes T, DeLoof A (1990) Isolation and identification of a sulfakinin-like peptide with sequences homology to vertebrate gastrin and cholecystokinin from the brain of Locusta migratoria. In: McCafferty AR, Wilson ID (eds) Chromatography and isolation of insect hormones and pheromones. Plenum Press, New York, pp 231

Tibbetts M, Nichols R (1993) Immunocytochemistry of sequencerelated neuropeptides in Drosophila melanogaster. Neuropeptides 24:321

White K, Hurteau P, Punsal P (1986) Neuropeptide FMRFamidelike immunoreactivity in Drosophila melanogaster: development and distribution. J Comp Neurol 247:430

Veenstra JA (1990) Isolation and structure of two gastrin/CCKlike neuropeptides from the American cockroach homologues to the leucosulfakinins. Neuropeptides 14:145

Yamada H, Imoto T, Fujita K, Okazaki K, Motomura M (1981) Selective modification of aspartic acid-101 in lysozyme by carbodiimide reaction. Biochemistry 20:4836 